In Situ

Revue des patrimoines

\section{In Situ}

Revue des patrimoines

$8 \mid 2007$

Le patrimoine industriel

\title{
La Morue Normande, de la conserverie au musée
}

\section{Florence Levert}

\section{OpenEdition}

\section{Journals}

Édition électronique

URL : http://journals.openedition.org/insitu/3028

DOI : $10.4000 /$ insitu.3028

ISSN : 1630-7305

\section{Éditeur}

Ministère de la culture

\section{Référence électronique}

Florence Levert, "La Morue Normande, de la conserverie au musée », In Situ [En ligne], 8 | 2007, mis en ligne le 01 mars 2007, consulté le 30 avril 2019. URL : http://journals.openedition.org/insitu/3028 DOI : 10.4000/insitu.3028

Ce document a été généré automatiquement le 30 avril 2019

\section{(c) (i) $\odot$}

In Situ Revues des patrimoines est mis à disposition selon les termes de la licence Creative Commons Attribution - Pas d'Utilisation Commerciale - Pas de Modification 4.0 International. 


\title{
La Morue Normande, de la conserverie au musée
}

\author{
Florence Levert
}

1 Traditionnellement à Fécamp, on ne sèche pas la morue. Le climat est trop humide. C'est la morue verte, denrée issue de la maturation du poisson dans le sel qui la conserve, que l'on consomme et commercialise ${ }^{1}$.

2 La morue est, par principe, un produit qui s'exporte loin des centres de production ${ }^{2}$. Par ailleurs, il est souvent arrivé que des pêcheurs fécampois, au retour des bancs, débarquent leur cargaison à Bordeaux ou bien encore à Port de Bouc, à Sète (anciennement Cette) ou même au Portugal.

\section{Sécher la morue : une activité nouvelle pour les Fécampois}

3 Dans la première moitié du $\mathrm{XX}^{\mathrm{e}}$ siècle, pourtant, des Fécampois mettent au point des méthodes pour sécher la morue chez eux ${ }^{3}$. Les morues séchées sont ensuite exportées vers des régions consommatrices: Sud et Est de la France, Afrique du Nord, Italie, Antilles, Brésil, etc.

4 Parmi eux, Joseph Duhamel, fondateur en 1913 de la maison d'armement Les Pêcheries de Fécamp, investit dans ce nouveau procédé de conservation. En 1926, avec son gendre Honoré York, il fonde La Morue Normande $e^{4}$. La société est implantée au cœur du port de Fécamp. On y sèche la morue débarquée des chalutiers de l'armement des Pêcheries. On y conditionne également la morue salée, repaquée ${ }^{5}$ ou en filets.

5 Au début du siècle dernier, une productivité morutière décuplée a favorisé une démarche industrielle audacieuse ${ }^{6}$. Elle explique l'investissement considérable que représente l'établissement de cette nouvelle activité de sécherie de morue.

6 Joseph Duhamel s'inscrit catégoriquement dans cette modernité comme avant lui la famille Le Borgne avec Les sécheries de morue de Fécamp et l'armateur Legasse avec la sécherie La morue française. Devenus à la fois armateurs et négociants, ces nouveaux chefs 
d'entreprise maîtrisent l'ensemble de la chaîne de production, de la pêche à l'expédition du produit conditionné. En offrant une production de morue séchée adaptée à la demande étrangère, ils maintiennent la prospérité de leur maison d'armement.

7 Laissons à Joseph Duhamel lui-même le soin d'argumenter sur les avantages de ce principe : «La Morue Normande travaille en participation avec [l'entreprise] les Pêcheries qui a fait l'apport de l'immeuble dans lequel nous avons monté notre installation de stockage et de séchage des marchandises (...) Nous avons le sentiment d'avoir créé une affaire saine et viable dont l'avenir, malgré les risques afférents au côté spéculatif de l'article, ne peut être que très encourageant, grâce à l'appui de nos amis des Pêcheries de Fécamp, dont l'armement compte parmi les mieux organisés, autorisant à notre direction une politique d'achat très souple, basée sur toutes les positions. En compensation de cette situation, nous devons reconnaître que notre existence à leurs côtés, permet aux Pêcheries de Fécamp de ne pas avoir à redouter la carence totale d'acheteurs et de maintenir les prix des contrats lorsque les acheteurs de mauvaise foi arguent d'une mauvaise préparation pour obtenir des bonifications. Notre avenir est basé sur cette entente, sinon nous serions placés dans la multitude des négociants dont la situation n'aurait pas, par simple esprit de prudence, tenté votre fondateur. $»^{7}$

\section{La sécherie d'après-guerre}

"Ne faire qu'une chose mais la bien faire ». Telle est l'exergue au petit livret édité en 1950 à l'occasion de l'inauguration de la nouvelle sécherie de la famille York-Duhamel. Nous ne doutons pas de la qualité du travail effectué à La Morue Normande. Le moins que l'on puisse dire toutefois, c'est que l'usine de La Morue Normande ne gardera pas cette spécialité exclusive bien longtemps!

Figure 1

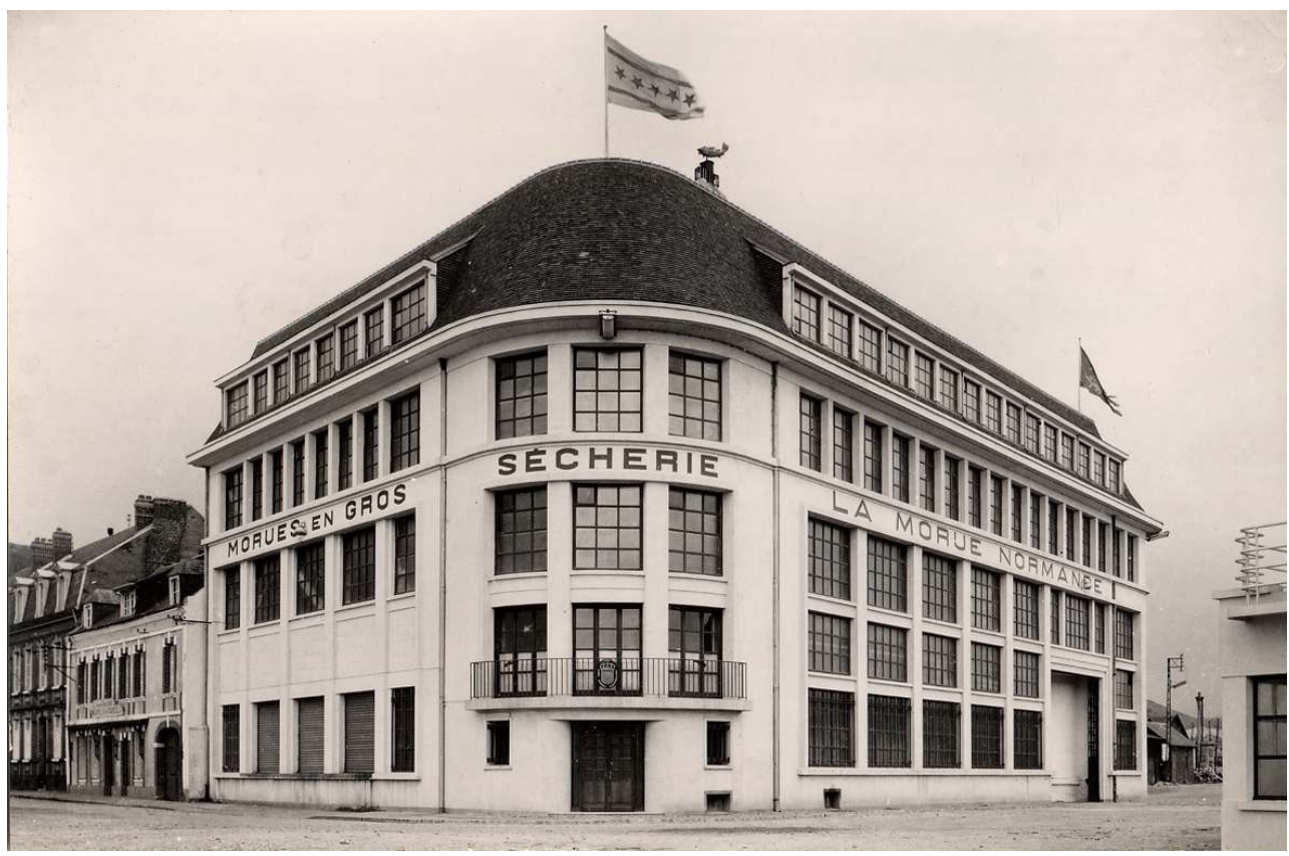

La Morue Normande en 1950. Photographie de Bergoin.

(c) Musée de Fécamp, collection Jean York. 
Figure 2

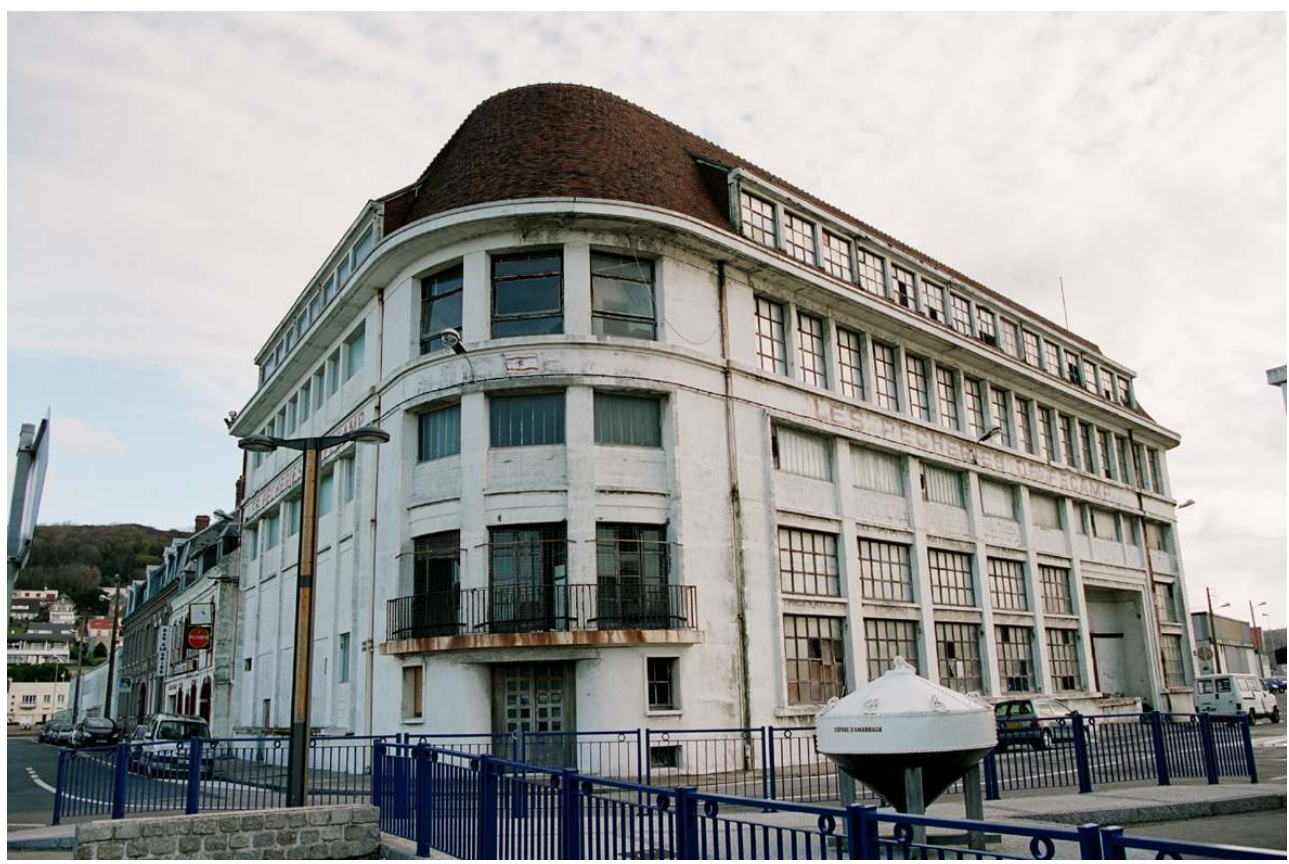

Le bâtiment aujourd'hui.

Photographie Imagery, novembre 2004.Droits réservés.

Figure 3

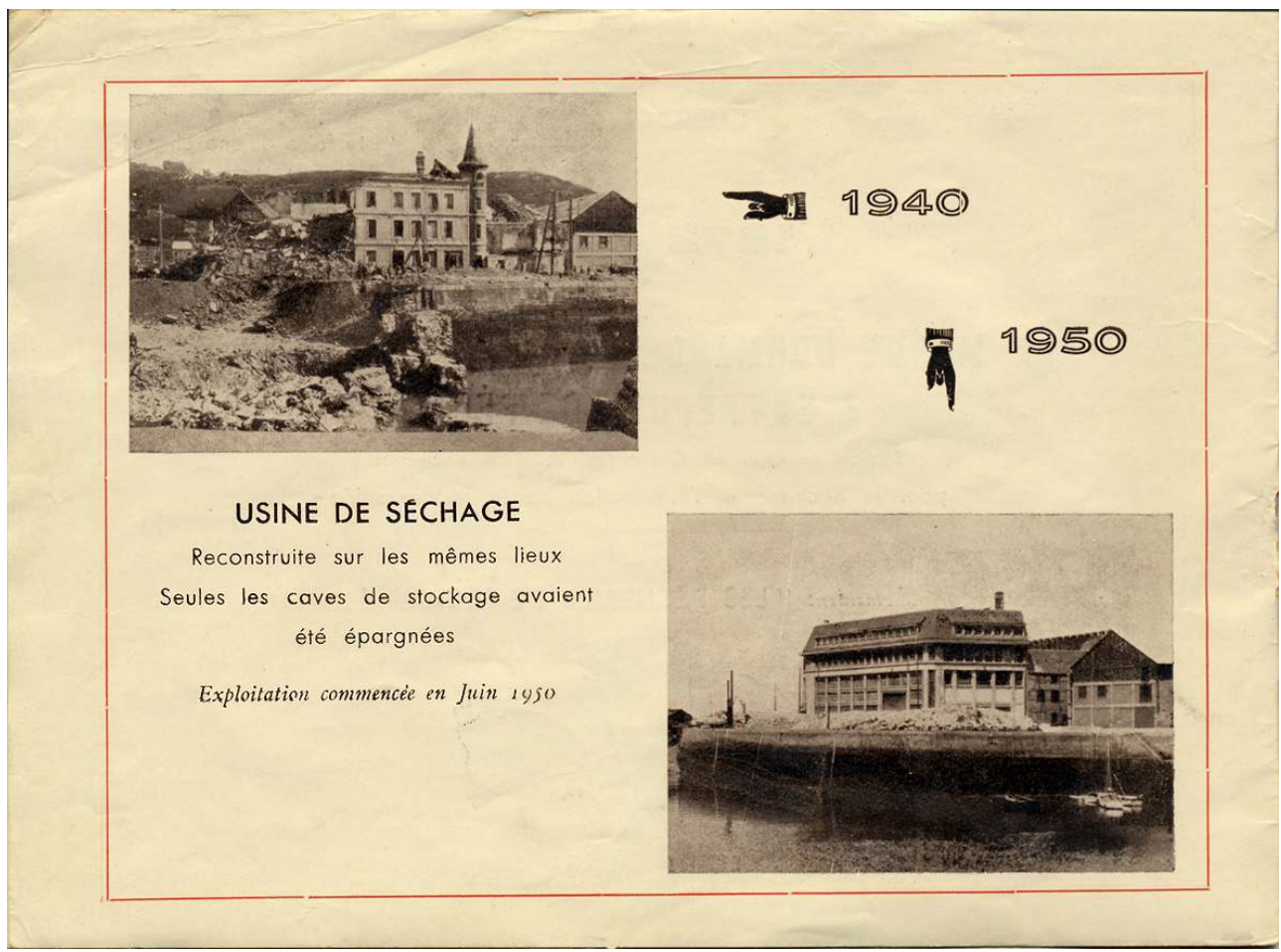

La reconstruction de la sécherie de La Morue Normande. Planche tirée du petit livret édité en 1950 à l'occasion de l'inauguration de la nouvelle sécherie.

Archives municipales de Fécamp. Droits réservés. 
9

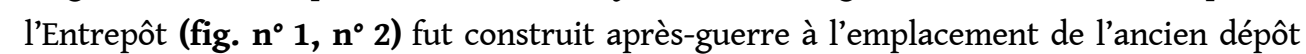
de sel, propriété de la famille, détruit en 1940 (fig. n 3). Il est conçu par l'architecte parisien André Hamayon ${ }^{8}$ et réalisé par Florentin Pollet, entrepreneur fécampois.

10

Cette sécherie est fonctionnelle et moderne : les espaces et les circuits du mouillé et du sec sont bien distincts. Elle se développe sur quatre niveaux bien séparés (deux sont consacrés au mouillé, un au séchage et un au sec). La circulation du poisson est assurée par deux monte-charge différents, un pour le mouillé, l'autre pour le sec.

11 A peine débarquée des navires de l'armement des Pêcheries, la morue salée est entreposée en piles ou bien en bacs au rez-de-chaussée du bâtiment (fig. $\mathbf{n}^{\circ} 4$ ). Selon les souvenirs de Jean York ${ }^{9}$, un progrès considérable est alors amené par la réfrigération (température entre 8 et $10^{\circ} \mathrm{C}$.). Il était toujours à craindre, en effet, que la morue ne " prenne le rouge » ${ }^{10}$.

\section{Figure 4}

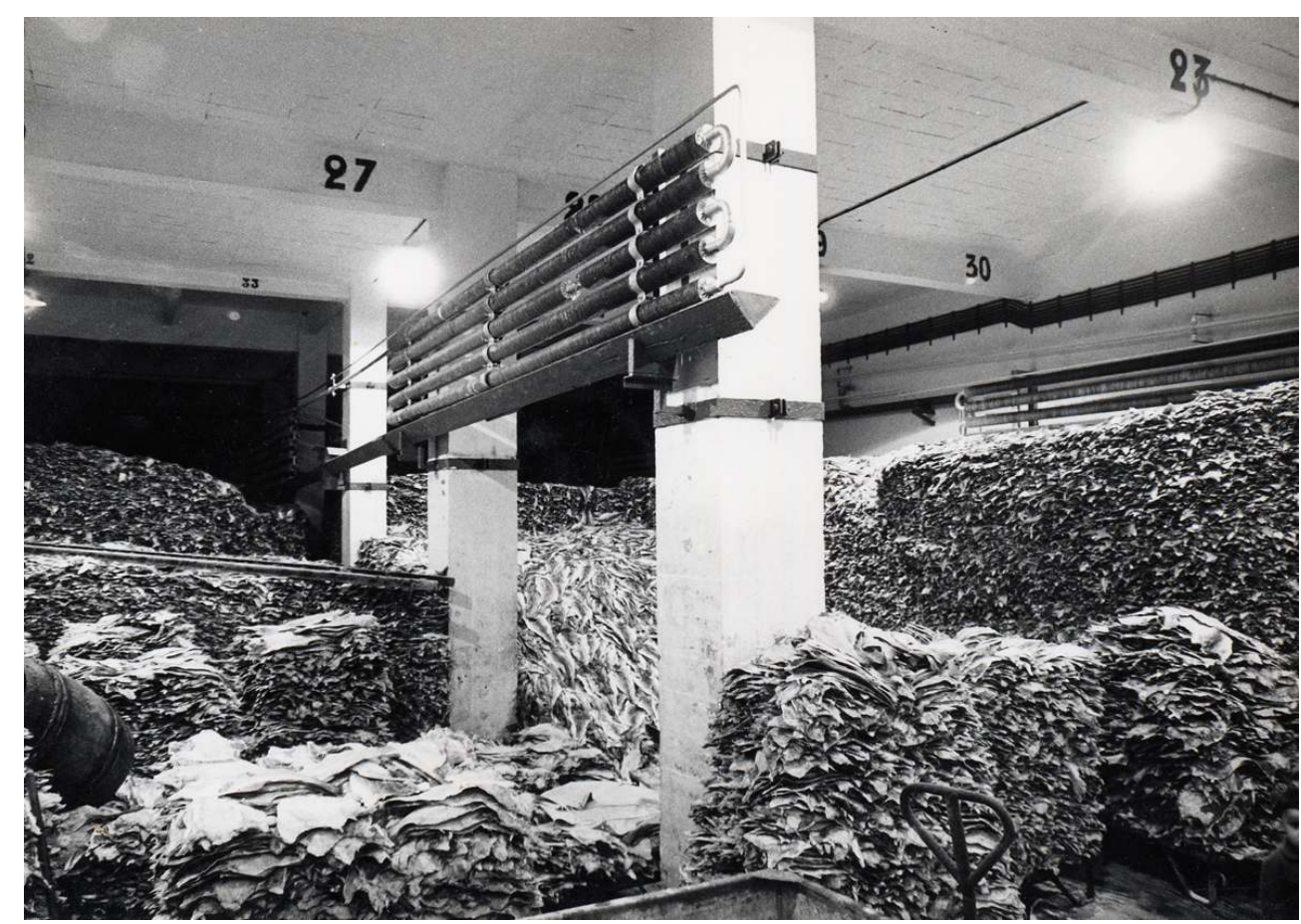

Piles de morues salées. Photographie Bergoin, vers 1950.

(c) Musée de Fécamp, collection Jean York.

12 Extrait du stockage au fur et à mesure des besoins, le poisson est débarrassé de son sel en surface à l'aide de brosseuses rotatives puis il est rincé à l'eau claire. Ces opérations prennent place dans un espace aménagé sur le côté sud du premier niveau (fig. $\mathbf{n}^{\circ}$ 5). 
Figure 5

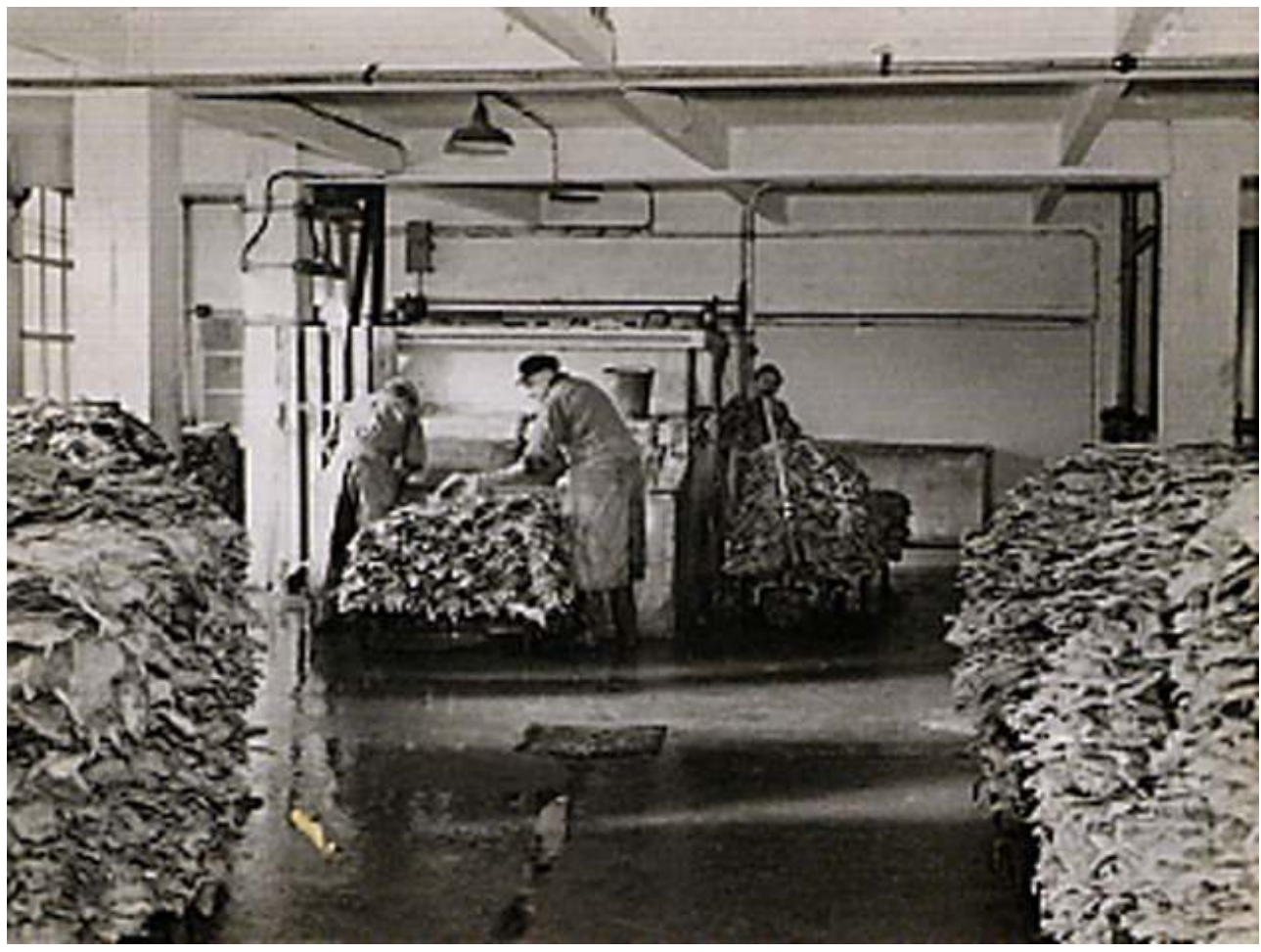

Après avoir été brossées, les morues sont lavées à grande eau. Elles subissent ensuite un passage dans une solution de bisulfite de soude afin que la chair de la morue soit bien blanche. Les hommes sont affectés à ces tâches. Photographie Bergoin, vers 1950.

(c) Musée de Fécamp, collection Jean York.

13 La morue est ensuite acheminée par monte-charge au deuxième niveau où des ouvrières la suspendent sur des chariots (fig. $\mathbf{n}^{\circ} \mathbf{6}$ ). Elle y reste quelques heures afin de perdre une partie de son eau. Les chariots sont alors dirigés vers le quatrième niveau où se trouve l'espace de séchage proprement dit (fig. $\mathbf{n}^{\circ} 7$ ). Les chariots sont introduits dans des tunnels ventilés d'air chaud (à environ $27^{\circ} \mathrm{C}$. et $55 \%$ d'hygrométrie). Ils y restent de deux à quatre heures selon le pourcentage de dessiccation désiré ${ }^{11}$. Une fois l'opération terminée, la morue est mise dans l'ascenseur réservé au produit sec et envoyée à l'étage du dessous. 
Figure 6

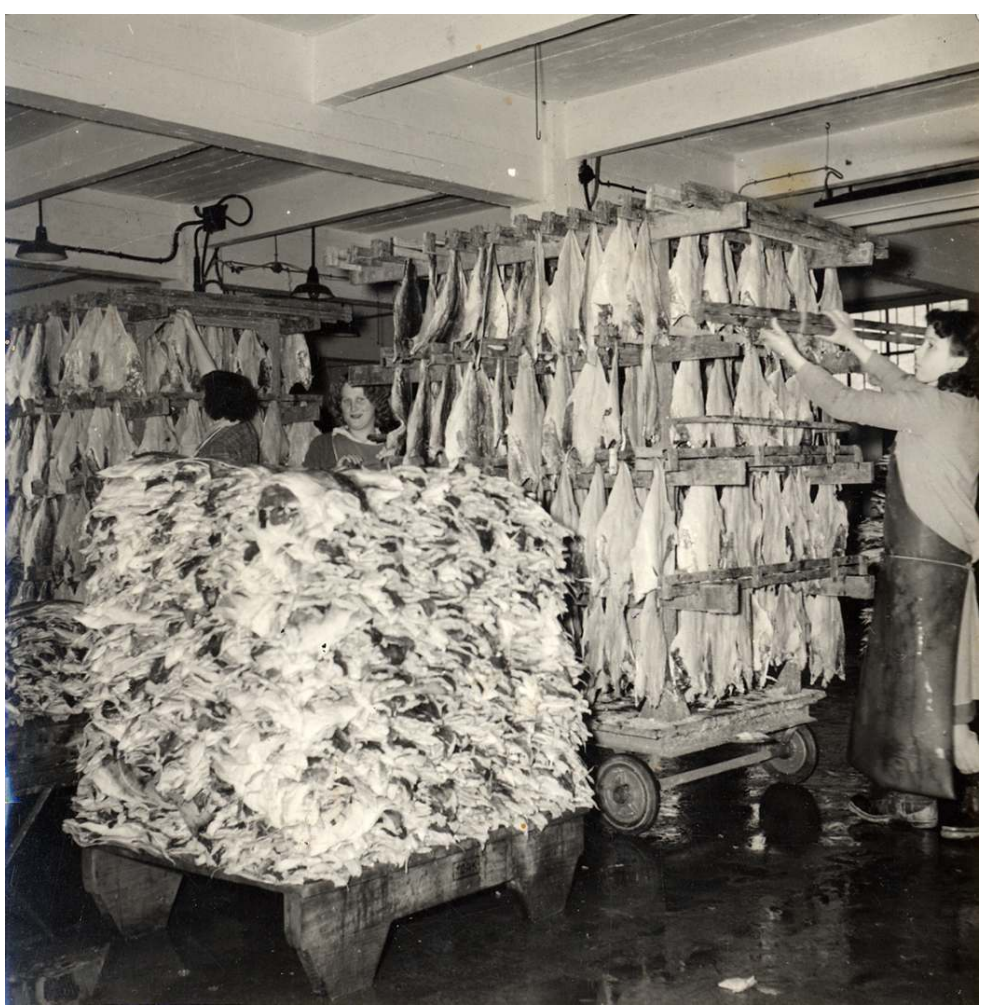

La mise sur chariots de la morue destinée à être séchée. Les femmes sont affectées à cette tâche. Vers 1960.

(c) Musée de Fécamp, collection Jean-Marie Lefrançois. 
Figure 7

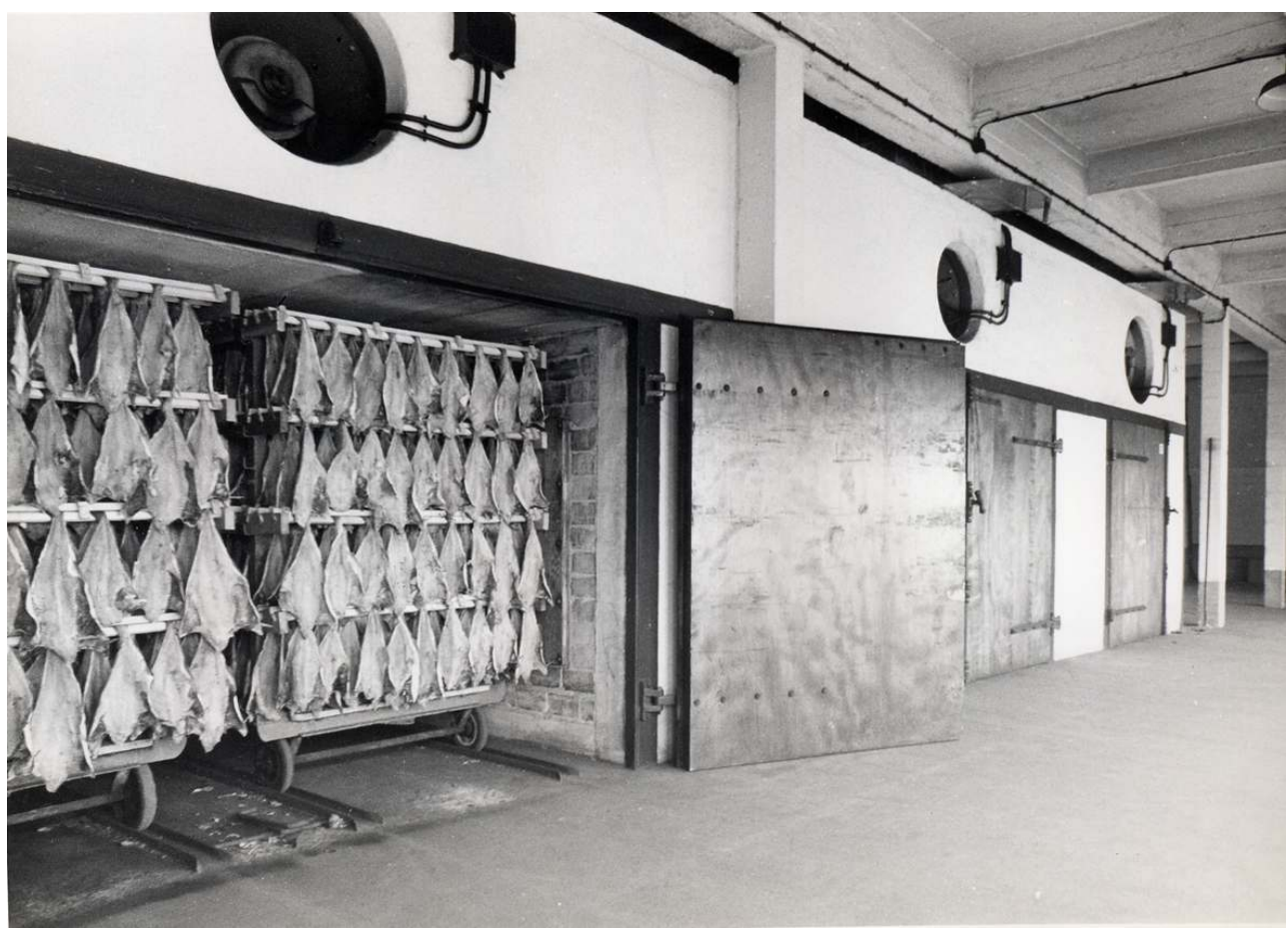

Un tunnel de séchage. Photographie Bergoin, vers 1950.

(c) Musée de Fécamp, collection Jean York.

14 Ce troisième niveau est dédié au conditionnement. La morue est décrochée des chariots, emballée en sacs de jute, mise en caisses (fig. $\mathbf{n}^{\circ} \mathbf{8}$ ) ou bien compressée dans des boucauds ${ }^{12}$ en bois (fig. $\mathbf{n}^{\circ}$ 9). A cet étage, un espace important est consacré au stockage du produit fini. Les jours d'expédition, les colis sont descendus au rez-de-chaussée pour être chargés dans un camion de livraison 
Figure 8

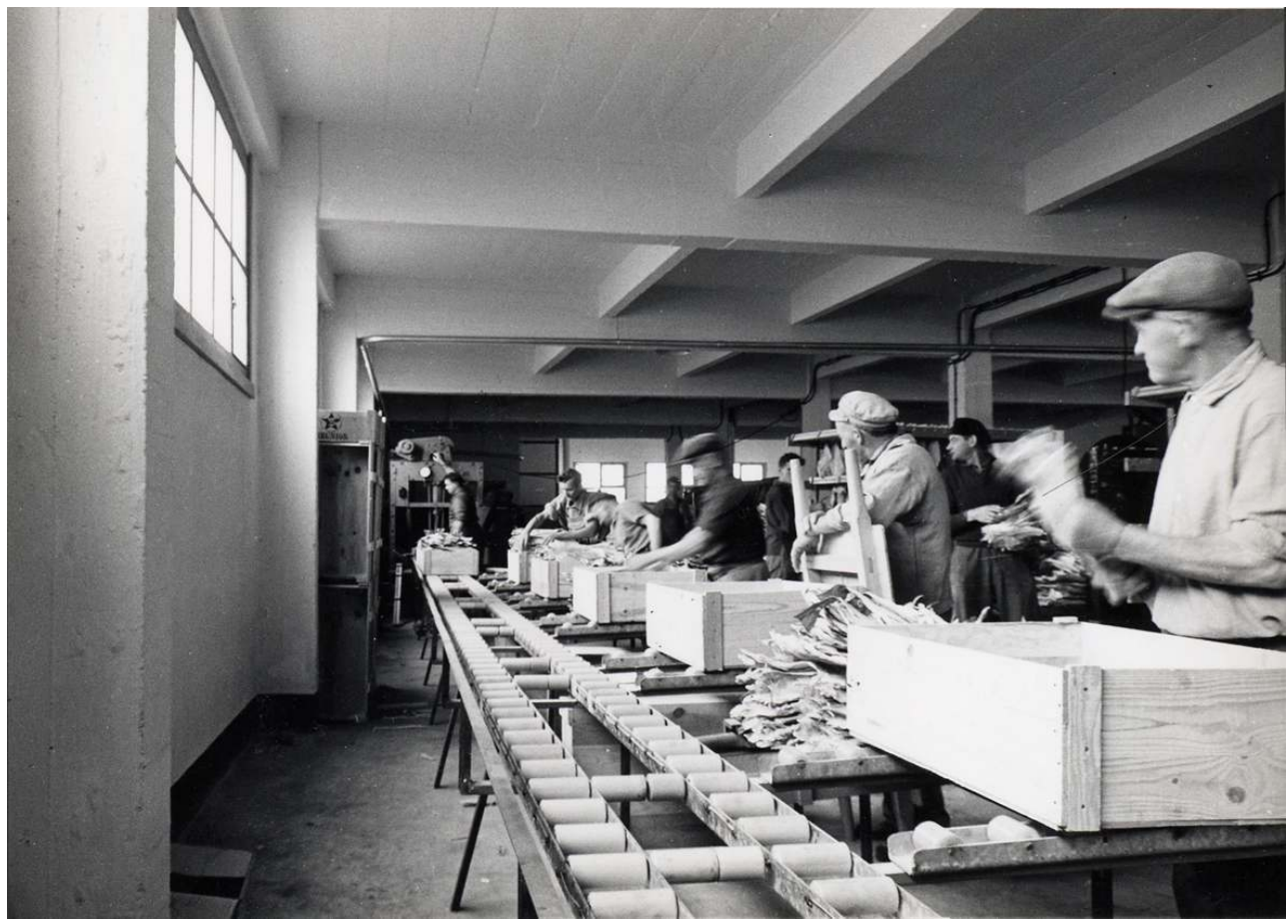

La mise en caisse de la morue séchée. Photographie Bergoin, vers 1950.

(c) Musée de Fécamp, collection Jean York.

Figure 9

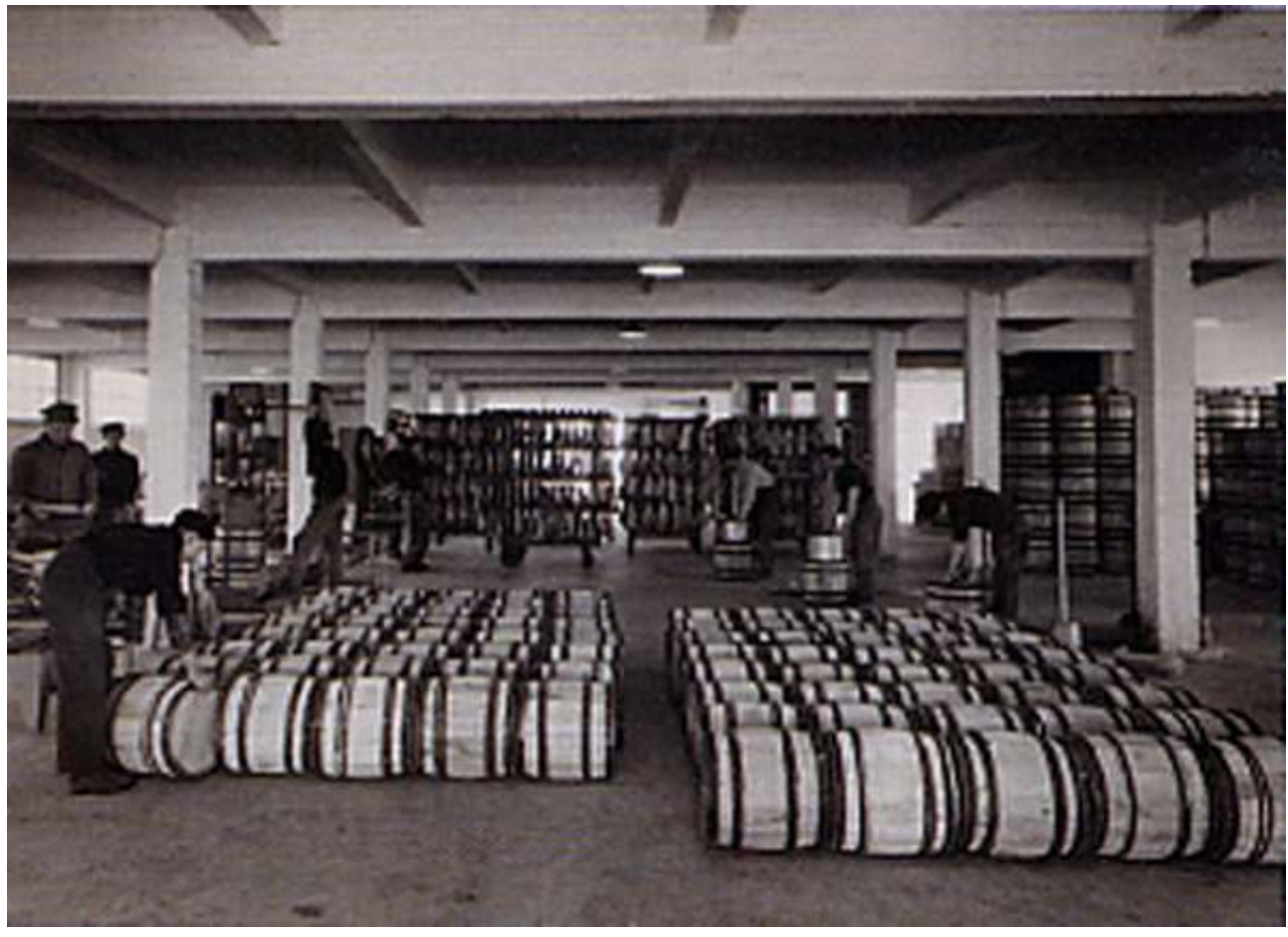

Le conditionnement de la morue dans des « boucauds ». Photographie Bergoin, vers 1950

(c) Musée de Fécamp, collection Jean York. 
Le quai de chargement est aménagé sur la façade sud (fig. $\mathbf{n}^{\circ} \mathbf{1 0}$ ).

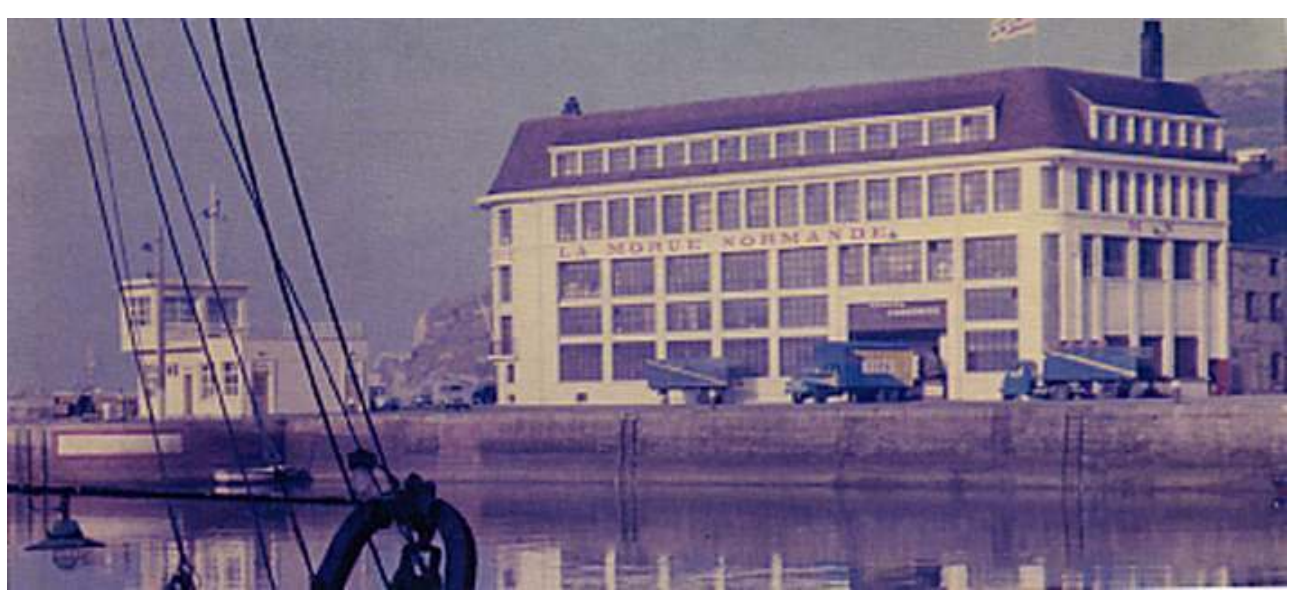

Vue de la façade sud de La Morue Normande et de son quai d'expédition. Photographie anonyme destinée à illustrer une carte de vœux de l'entreprise. Vers 1965.

Archives municipales de Fécamp. Droits réservés. distinction entre les quais permettait l'expédition de morue séchée même en période de retour des navires terre-neuviers ${ }^{13}$.

\section{Vers une diversification des activités ${ }^{14}$} représente La Morue Normande en témoigne. Ils savent également que le marché de la morue exige une grande souplesse. Cette nécessité a inspiré l'architecture particulière du bâtiment de La Morue Normande.

L'usine ne comporte aucun mur porteur. A chaque niveau, un réseau de piliers supporte l'étage supérieur. Les espaces peuvent ainsi être réorganisés autant de fois que nécessaire.

Par principe, les slogans publicitaires ne sont pas gravés dans le marbre... En 1960, la formule d'Honoré York « Ne faire qu'une chose mais la bien faire » est devenue obsolète. Dès lors, en effet, La Morue Normande connaît une diversification de ses activités qui entraîne une grande polyvalence des espaces de travail. Il ne reste alors plus grand-chose de la fonctionnalité première du bâtiment avec ses circuits sec et mouillé bien distincts.

La période qui débute est celle d'une cohabitation de la morue séchée avec des productions plus traditionnelles à Fécamp. Une production de filets de harengs fumés est intégrée sur le site de La Morue Normande. A terme, elle occupera l'exclusivité des activités sur le site du Grand-Quai.

21 Au rez-de-chaussée, les espaces de stockage dévolus à chaque produit (morue verte ou hareng salé en saumure) sont nettement séparés. Sur le côté sud, comme à la période précédente, les hommes brossent et lavent la morue. A proximité, les harengs salés destinés à être sauris sont mis à la trempe. Au premier étage s'installe l'essentiel de l'activité de transformation du hareng. 

L'entreprise fait donc l'acquisition d'une dizaine de fours alimentés en sciure de bois ${ }^{16}$ dans lesquels vont être fumés les harengs (fig. $\mathbf{n}^{\circ} \mathbf{1 1}$ ).

23

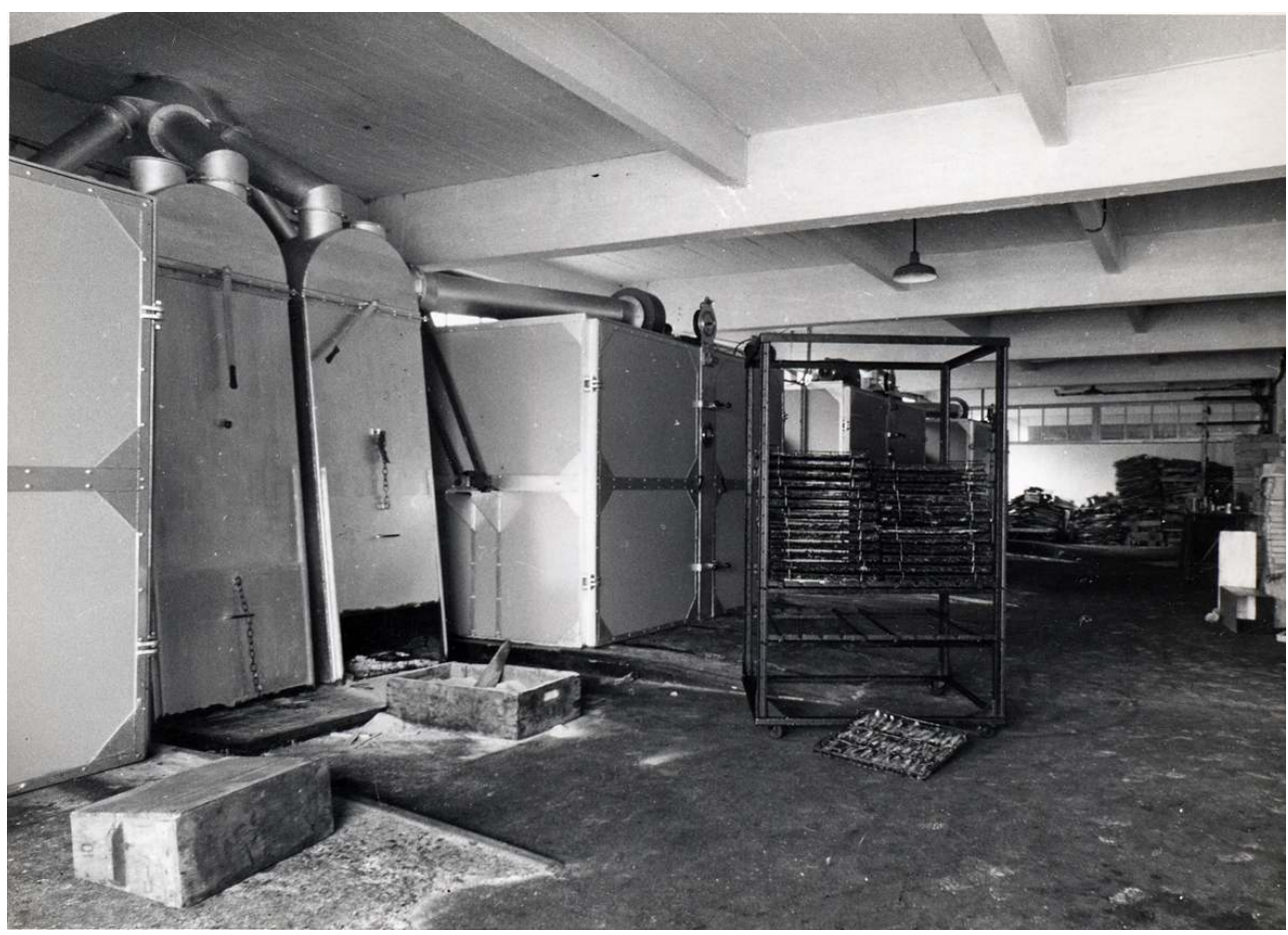

Les fours Tri-Sor. Vers 1960.

(c) Musée de Fécamp, collection Jean-Marie Lefrançois.

24 Afin de maximiser le rendement, la fumaison est raccourcie en traitant préalablement le poisson. Un hareng étêté, vidé et ouvert en deux sera fumé en trois fois moins de temps qu'il ne faut en saurisserie traditionnelle. L'entreprise achète une machine Baader ${ }^{17}$ qui automatise ces opérations.

Diversification des activités, impératifs de productivité et mécanisation sont autant de raisons imbriquées qui redéfinissent le métier des filetières. Leur travail se limite alors à enlever la peau du poisson et à le couper en deux pour obtenir les filets ${ }^{18}$.

$\mathrm{Au}$ premier étage, l'espace dévolu au hareng comprend donc trois zones distinctes. A proximité des monte-charges par lesquels le poisson arrive du rez-de-chaussée, un homme travaille sur la Baader (fig. $\mathbf{n}^{\circ} \mathbf{1 2}$ ). 
Figure 12

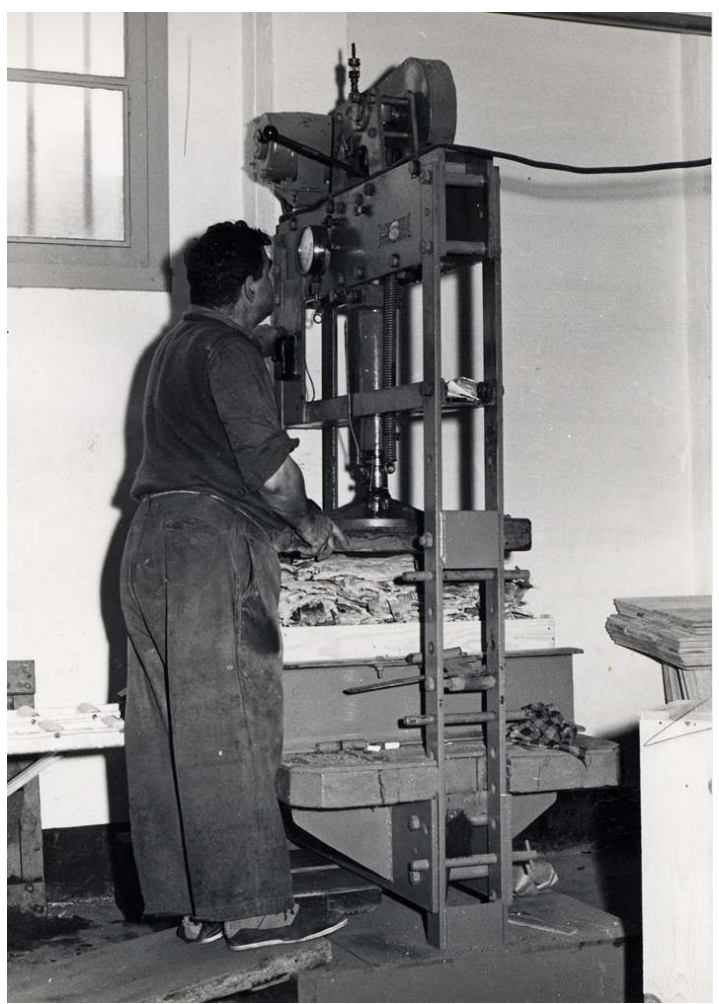

Les machines Baader qui étêtent, vident et coupent le poisson, ont d'abord été utilisées sur les bateaux morutiers. Elles apparaissent dans les années 1960. Les industries de transformation s'en équipent progressivement. Vers 1960.

(c) Musée de Fécamp, collection Jean-Marie Lefrançois.

Il reçoit un poisson entier. Il en fait un triangle de chair que des ouvrières accrochent sur des «ainets chimiques $»^{19}$. Elles en chargent des chariots. Une fois remplis, elles les passent au saurin ${ }^{20}$ par une porte coulissante.

Le responsable de la fumaison occupe le côté nord du bâtiment. Il est chargé d'alimenter les fours. Comme en saurisserie traditionnelle, le bois est le combustible et la sciure produit la fumée. Après avoir retiré les chariots des fours, il transmet les poissons aux filetières (fig. $\mathbf{n}^{\circ}$ 13) dont l'atelier communique avec le sien par une seconde porte coulissante. 
Figure 13

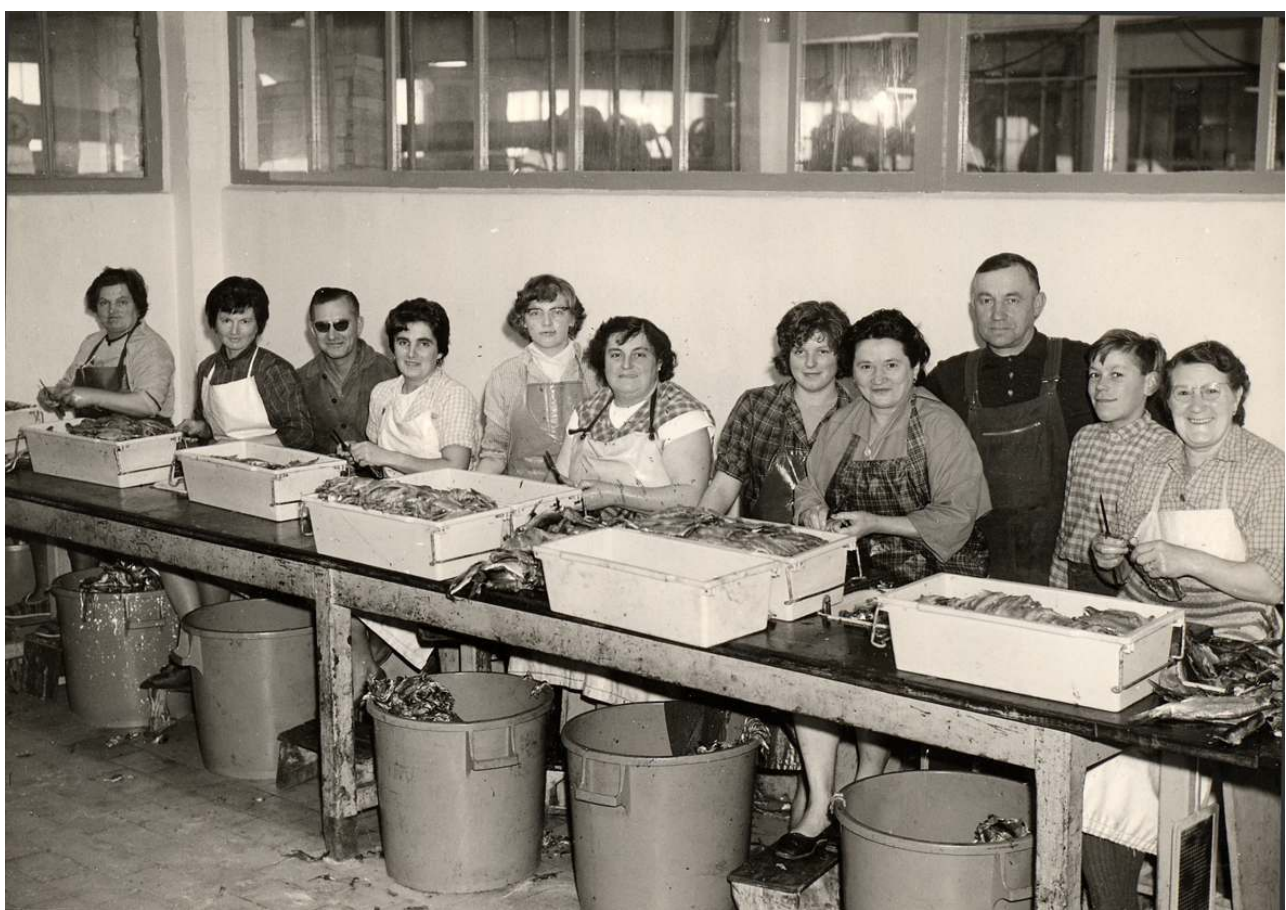

Une équipe de filetières au hareng et leurs contremaîtres. Vers 1960

(c) Musée de Fécamp, collection Jean-Marie Lefrançois.

Durant cette période de cohabitation où sont traités à la fois morue et hareng, l'accrochage de la morue sur les chariots se maintient au premier étage tout en occupant une place moins importante qu'auparavant.

$30 \mathrm{Au}$ deuxième étage, on trouve l'emballage de la morue, le conditionnement du hareng (fig. $\left.\mathbf{n}^{\circ} \mathbf{1 4}, \mathbf{n}^{\circ} 15\right)$ et le stockage des produits prêts pour l'expédition. De nouveaux cloisonnements sont réalisés. 
Figure 14

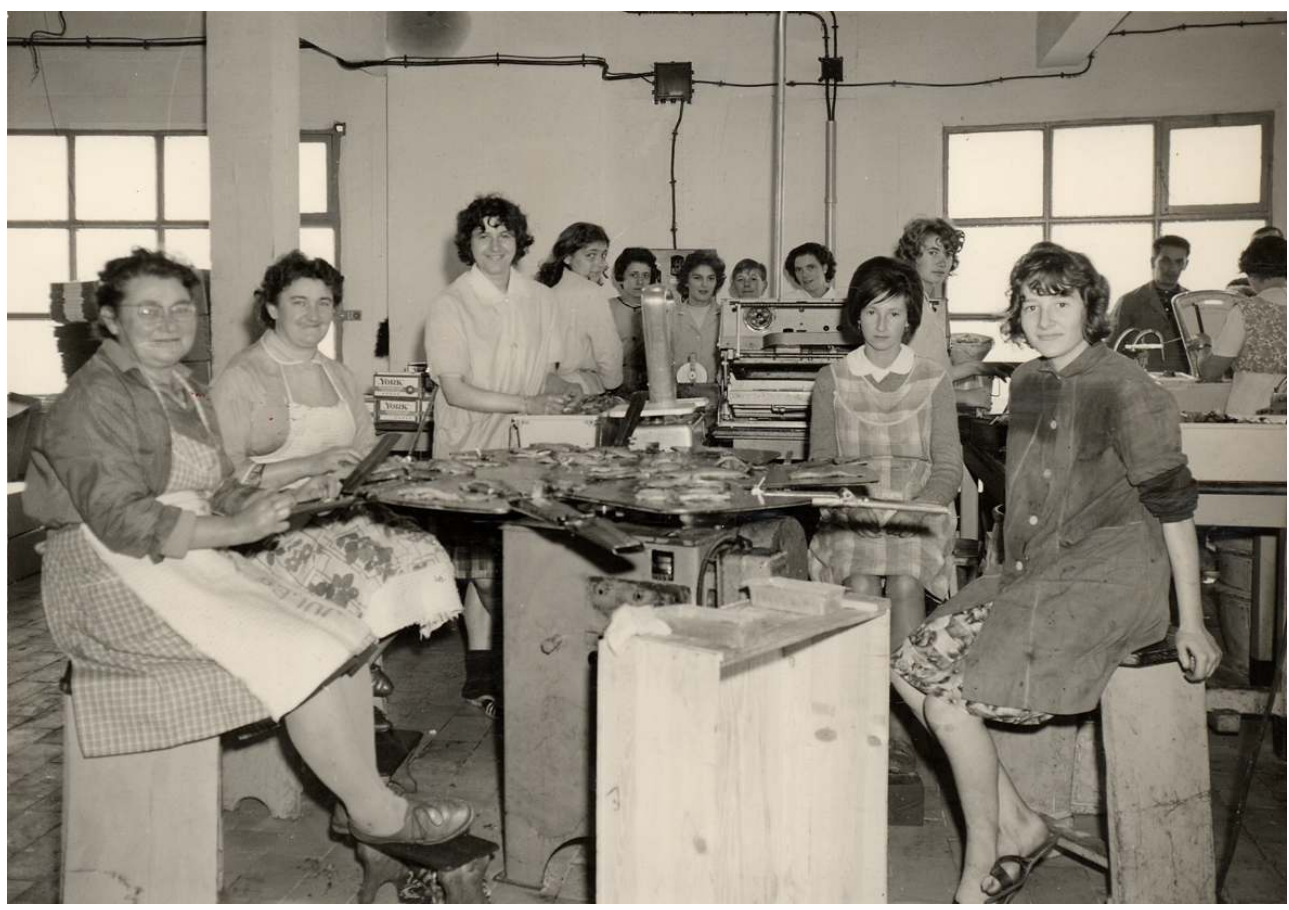

Le conditionnement du hareng. Vers 1960

(c) Musée de Fécamp, collection Jean-Marie Lefrançois

Figure 15

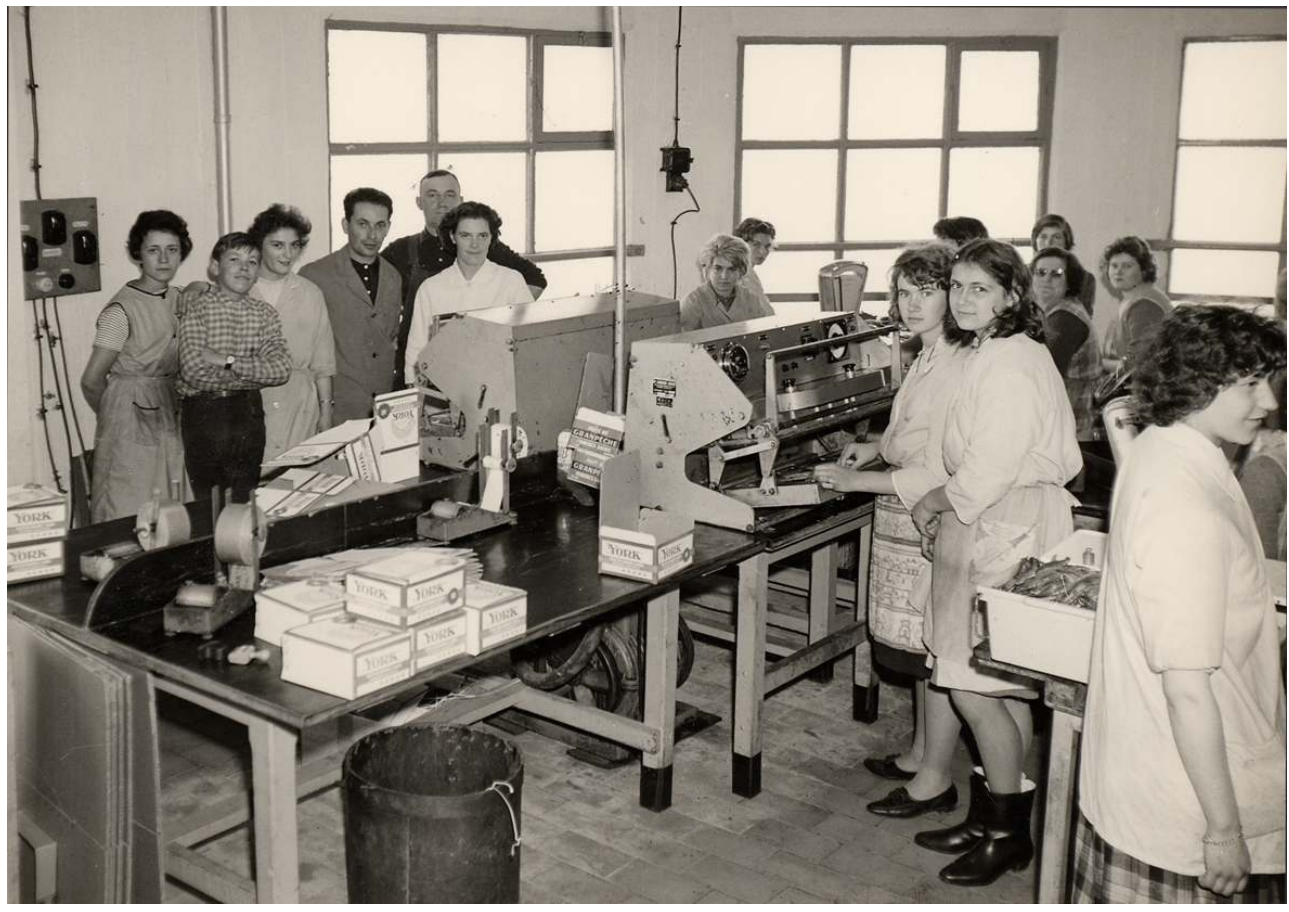

Le conditionnement du hareng. Vers 1960.

(c) Musée de Fécamp, collection Jean-Marie Lefrançois.

31 Rien ne change au troisième étage où les tunnels de séchage sont toujours en activité. 

que ressentent les armateurs fécampois à l'aube des années soixante. Elle pare au ralentissement de la production morutière, d'autant que la flexibilité du bâtiment la rend facilement réalisable.

A cette époque, les armateurs commencent à parler de la raréfaction des ressources, à s'interroger sur la rentabilité du maintien d'une flotte terre-neuvière, à solliciter les aides publiques et semblent vouloir sensibiliser l'opinion ${ }^{21}$.

Dans le même temps, ils investissent dans des navires congélateurs. Conçus pour chaluter dans les mers froides, transformer et conserver le poisson en filets sous forme de plaques surgelées, ces usines flottantes dénotent pourtant la confiance des investisseurs ${ }^{22}$.

\section{Espaces et personnel}

Formidable machine à recevoir, stocker, produire et expédier, La Morue Normande n'en est pas moins un lieu où des hommes et des femmes, patrons, contremaîtres et ouvriers travaillent, circulent, s'approprient des espaces, les détournant parfois de leurs fonctionnalités premières. Conçu pour l'excellence, en qualité comme en quantité, le bâtiment applique de stricts principes d'organisation sociale voulus par son commanditaire. L'usine est le lieu où les hommes respectent les règles sociales inscrites dans le process, comme elles le sont dans le projet architectural. Par ailleurs, les hommes et les femmes qui ont travaillé à La Morue Normande, sans jamais compromettre la fonction première de l'usine, lui ont adjoint d'autres usages.

L'usine, désaffectée, est aujourd'hui devenue génératrice de parole ${ }^{23}$. Les mots recueillis nous amèneront à saisir les modalités d'articulation entre technicité et données sociales et culturelles implicites nées de l'usage du bâtiment. Je reviendrai sur ce point.

37 A la seconde époque, alors que l'usine diversifie ses activités, toutes les catégories de personnel accèdent au bâtiment par la même porte, située à l'angle du Grand-Quai et du quai de l'Entrepôt $t^{24}$. Derrière cette porte se trouve un palier exigu. Ce passage commun, si petit soit-il, rappelle que chacun, du plus modeste trieur de poisson au Présidentdirecteur général, travaille pour satisfaire un seul et même objectif.

Face à l'entrée, derrière une grande porte vitrée à deux vantaux, se trouve le hall d'accueil (fig. $\mathbf{n}^{\circ} \mathbf{1 6}$ ). Sur le sol, une mosaïque représente le pavillon étoilé de la maison. Cet espace débouche sur un escalier de bois qui mène au bureau du Président-directeur général. Doté de trois fenêtres, il bénéficie d'un beau panorama sur l'espace portuaire ${ }^{25}$. 
Figure 16

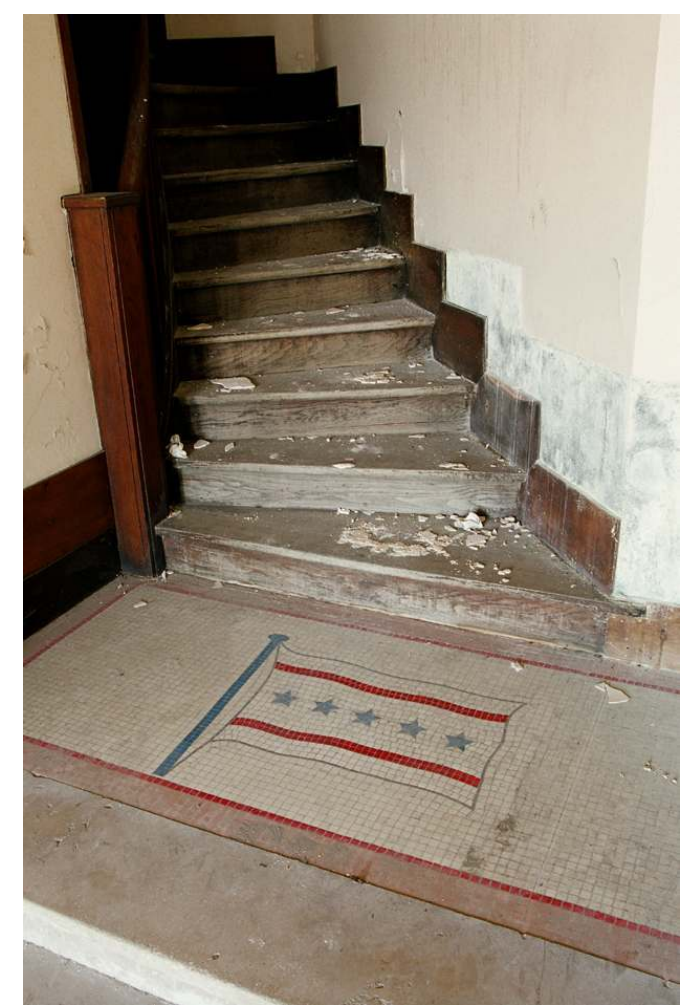

Le hall d'accès au bureau.

Photographie Imagery, novembre 2004. Droits réservés.

Sur le palier, ouvriers et ouvrières, quant à eux, vont à gauche. Trois marches séparent cette petite entrée commune d'un espace d'accueil un peu plus vaste où se trouve le règlement intérieur. Au fond, à droite, une porte donne accès aux espaces de stockage du rez-de-chaussée.

A gauche, un escalier mène aux étages via la zone des vestiaires et sanitaires réservée au personnel ouvrier. Aménagé à l'entresol, cet espace se situe de plain-pied avec le bureau du Président-directeur général (fig. $\mathbf{n}^{\circ} \mathbf{1 7}$ ). Une communication est d'ailleurs possible entre les deux. En effet, l'escalier de béton qui mène de l'accueil des ouvriers aux vestiaires dessert, à droite au niveau de l'entresol, une porte en bois. Celle-ci est dotée d'un hublot vitré à hauteur de visage et il suffirait de la franchir pour se retrouver dans un couloir lambrissé au sein même de l'espace réservé à la direction. Pourtant, les ouvriers ne franchissaient jamais cette porte, réservée aux membres de la direction et au personnel d'encadrement pour rapidement passer des bureaux à l'espace de production. 
Figure 17

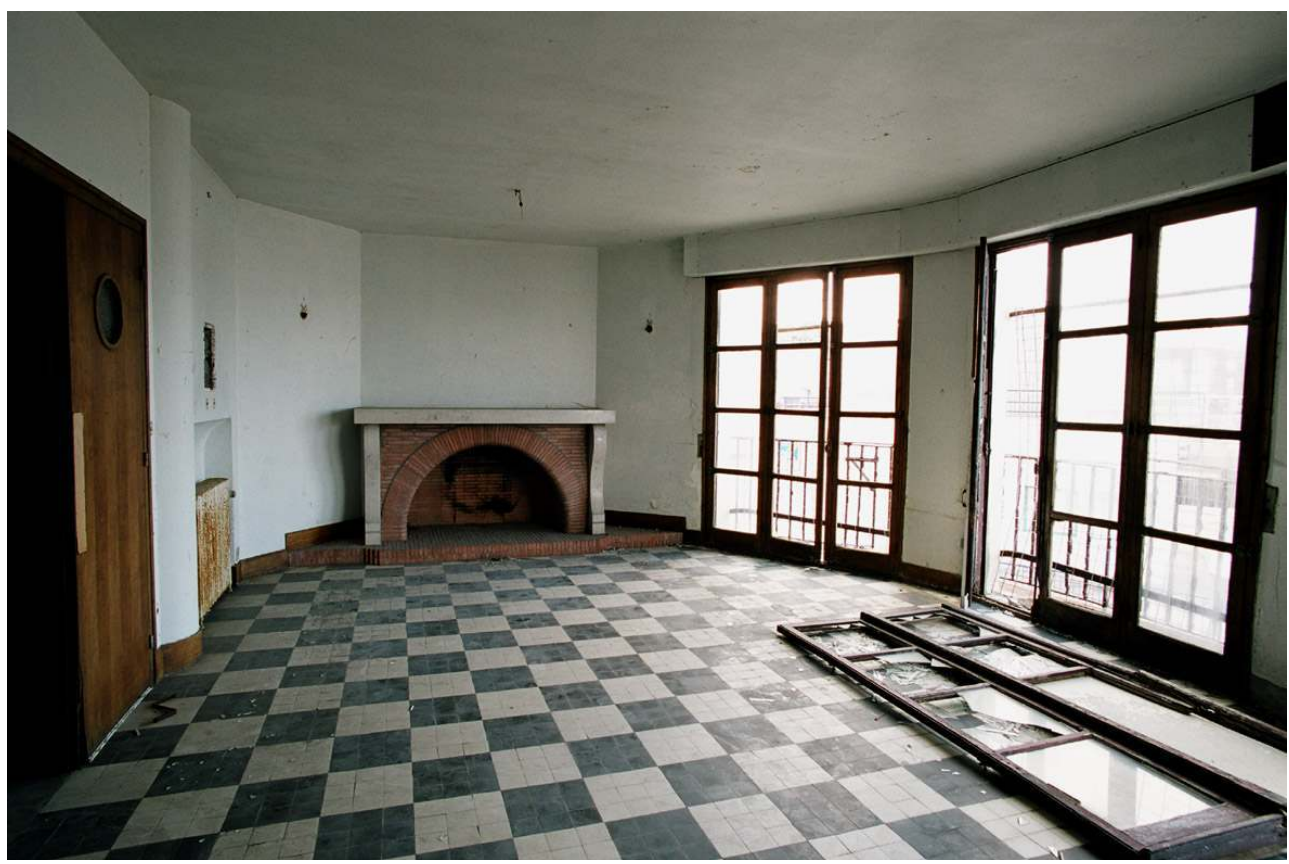

Le bureau de l'armateur.

Photographie Imagery, novembre 2004. Droits réservés.

41 A travers le hublot, l'ouvrier devinait le blanc aveugle du plafond et des murs du couloir. Bien que partiellement vitrée, cette porte n'invitait guère à l'échange mais fonctionnait bel et bien comme un miroir sans tain. Un visage omniscient risquait d'apparaître à tout moment. Par ces quelques détails de conception éprouvés, les ouvriers avaient conscience de la présence toute proche de l'autorité patronale. Une surveillance virtuelle mais pourtant bien réelle parce que véritablement efficace imposait le respect.

L'entresol donne accès au grand escalier du côté ouest du bâtiment distribuant les trois niveaux supérieurs. L'ouvrier entré le matin par la porte commune, passé aux vestiaires y déposer ses affaires et revêtir sa tenue de travail, emprunte exclusivement cet escalier. Contremaîtres et directeurs ont également accès à un petit escalier circulaire situé du côté est et desservant tous les niveaux, de l'espace de stockage à celui du séchage.

Plus la place était élevée dans la hiérarchie, plus le territoire d'action était nécessairement étendu. L'architecture fonctionnelle d'André Hamayon permettait que ce principe soit appliqué avec efficacité afin que la structure sociale se maintienne et que la productivité soit optimisée. Chacun à sa place et pas de perte de temps à déambuler.

Il faut noter que l'amplitude d'action des femmes était de loin la plus modeste. A la première époque, toutes ouvrières, elles n'avaient accès qu'à deux espaces de travail. En dehors des périodes de livraison, elles occupaient exclusivement le premier étage où elles étaient majoritaires. A l'époque du retour des morutiers, elles étaient nombreuses au rezde-chaussée où elles travaillaient alors avec des hommes au déchargement de la morue salée. Les femmes, dites plus attentives et plus sensibles, avaient la réputation d'être de bonnes recrues pour le triage du poisson ${ }^{26}$.

45 A partir des années 60 , des ouvrières travaillant à l'emballage du hareng occupent le deuxième étage. Le personnel féminin affecté au hareng se spécialise : certaines font 
carrière à l'emballage, d'autres au filetage, se cantonnant respectivement aux troisième et premier étages.

\section{Quand les chambres froides s'imposent}

En 1976, soit deux années avant le désarmement complet de la flotte terre-neuvière des Pêcheries, la production de morue est définitivement stoppée au Grand-Quai. Bien que l'inscription "Morue Normande » reste inscrite sur la façade jusqu'en 1978, hareng et saumon se partagent désormais l'ensemble de ce grand territoire ${ }^{27}$.

$\mathrm{Au}$ troisième étage, les tunnels de séchage sont démontés et une production de saumon fumé est installée ${ }^{28}$. Toutes les opérations nécessaires à sa confection y sont concentrées. Une chambre froide est installée le long du mur nord pour la conservation du saumon acheté congelé.

A proximité du monte-charge se trouve une grande table. Un homme y sale le poisson après décongélation et filetage. Des ouvrières déposent le saumon sur des claies dont elles garnissent des chariots qui sont ensuite placés dans des fours électriques alimentés en sciure de bois. Une fois fumés, les poissons sont refroidis afin d'en faciliter le tranchage. Des ouvrières installées autour d'une grande table découpent le saumon en fines tranches avec des appareils à couper le jambon. A une autre table, des femmes s'occupent de l'emballage. Il s'agit de reconstituer le saumon entier. Il est stocké en chambre froide.

Les trois autres niveaux sont alors exclusivement dévolus au hareng. Le hareng était jusqu'alors acheté salé ou bien salé sur place. C'est ainsi qu'il pouvait être conservé en bacs une année. Les fournisseurs proposent désormais un poisson congelé. Ce hareng, dit boneless, est par ailleurs étêté, vidé, et débarrassé de son arrête centrale.

La nature nouvelle du produit de base entraîne une réorganisation du rez-de-chaussée. Les bacs de stockage (à l'exception d'un seul) sont obstrués. Une grande chambre froide pour le stockage et des unités de décongélation sont installées. Une fois décongelés, les harengs sont salés. On peut doser la quantité de sel. Se développe alors un produit nouveau: le hareng doux. Le sel a perdu le caractère indispensable qu'il avait depuis toujours pour n'être plus qu'un élément gustatif facultatif.

51 A l'étage du dessus, le poste Baader est supprimé. Pour le reste, l'organisation est la même qu'à la période précédente : accrochage des harengs dans les chariots, saurissage et filetage. Au troisième niveau, l'organisation ne connaît pas de bouleversement important. Il semble toutefois que c'est à cette époque que les bureaux du directeur technique de l'usine et du contremaitre préposé aux expéditions y sont établis.

52 En 1982, l'activité de saumon fumé est délocalisée dans la zone industrielle de Babeuf à côté de Fécamp, où une usine lui est entièrement consacrée.

Dès lors, seul le hareng boneless est transformé au bâtiment du Grand-Quai ${ }^{29}$. L'activité perdure jusqu'en 1996, date à laquelle pour des raisons de normes vétérinaires européennes, la production est transférée sur la zone industrielle de Babeuf, à côté des unités de saumon et de produits surgelés. 


\section{Aux Pêcheries, les murs ont la parole}

54 L'histoire du bâtiment de La Morue Normande, destiné à l'origine à être une sécherie de morue, présente de façon exemplaire l'industrie de la pêche morutière fécampoise du XXe siècle, depuis l'enthousiasme et l'audace des premières années du siècle, l'apogée des années d'après-guerre jusqu'à l'arrêt définitif des départs pour Terre-Neuve. Elle nous apprend également qu'il serait vain de tenter de circonscrire un patrimoine maritime fécampo-fécampois. Il n'existe pas en tant que tel. En échanges, emprunts, adaptations... C'est là qu'il réside véritablement.

Nous avons souvent tendance, dans un schéma trop réducteur, à placer les activités de conservation et de commercialisation en aval des autres activités maritimes. Cette histoire nous révèle combien, au contraire, la pêche et la vie des hommes la pratiquant, leur ont été subordonnées.

Le grand bâtiment de La Morue Normande est aujourd'hui le lieu d'un beau et ambitieux projet muséographique. En 2008 sera inauguré le Musée des Pêcheries qui abritera l'ensemble des collections municipales.

57 Considéré comme le premier objet de la collection, l'immeuble des Pêcheries comprendra une zone, ou plutôt un parcours, consacré à son histoire. Y seront développés les thèmes évoqués plus haut: rôle des maisons d'armement et des négociants, conservation du poisson, réseaux marchands, congélation, fin de la pêche terre-neuvière, etc. Par ailleurs, certains éléments significatifs seront préservés. Il s'agit en particulier du bureau de l'armateur et de l'ensemble vestiaires et sanitaires des ouvrières.

58 A l'automne 2003, je me suis rendue sur les lieux avec des personnes qui y travaillèrent comme "femmes au poisson", ouvriers, contremaîtres et directeurs afin d'enregistrer leurs témoignages. Nous avons déambulé dans le bâtiment. Chacun a décrit les activités liées à chacune des zones de l'usine et m'a aidée à recomposer le circuit global de production à l'échelle du bâtiment.

59 Avec les "femmes au poisson", nous sommes allées partout. Elles ont découvert des espaces où elles n'avaient jamais pénétré en 20 ou 30 ans de carrière! Yvonne Langlois, ancienne filetière au hareng, n'avait jamais mis les pieds au troisième étage. Je l'y ai amenée. Elle était curieuse de pénétrer sur le territoire des "femmes au saumon ». "On ne s'aimait pas trop entre hareng et saumon. Le saumon, c'était pour les snobs et elles, c'était des snobs!» a-t-elle expliqué avant d'ajouter: "Dans les vestiaires, c'était pareil. Comme on s'arrangeait pas de trop, on bavachait pas ensemble, on mangeait pas ensemble. »

Yvonne n'était jamais entrée dans le bureau de l'armateur (voir fig. $\mathbf{n}^{\circ} \mathbf{1 7}$ ), comme nulle autre ouvrière d'ailleurs. L'expérience s'est révélée très forte tant pour elles que pour moi. Jusqu'au seuil, leur discours se situait dans le passé. Une fois la porte franchie, troublées, elles ont dès lors exprimé leurs souvenirs au présent : nous ne pouvions rester ici, ce n'était pas notre place, nous n'avions pas le droit. 
Figure 18

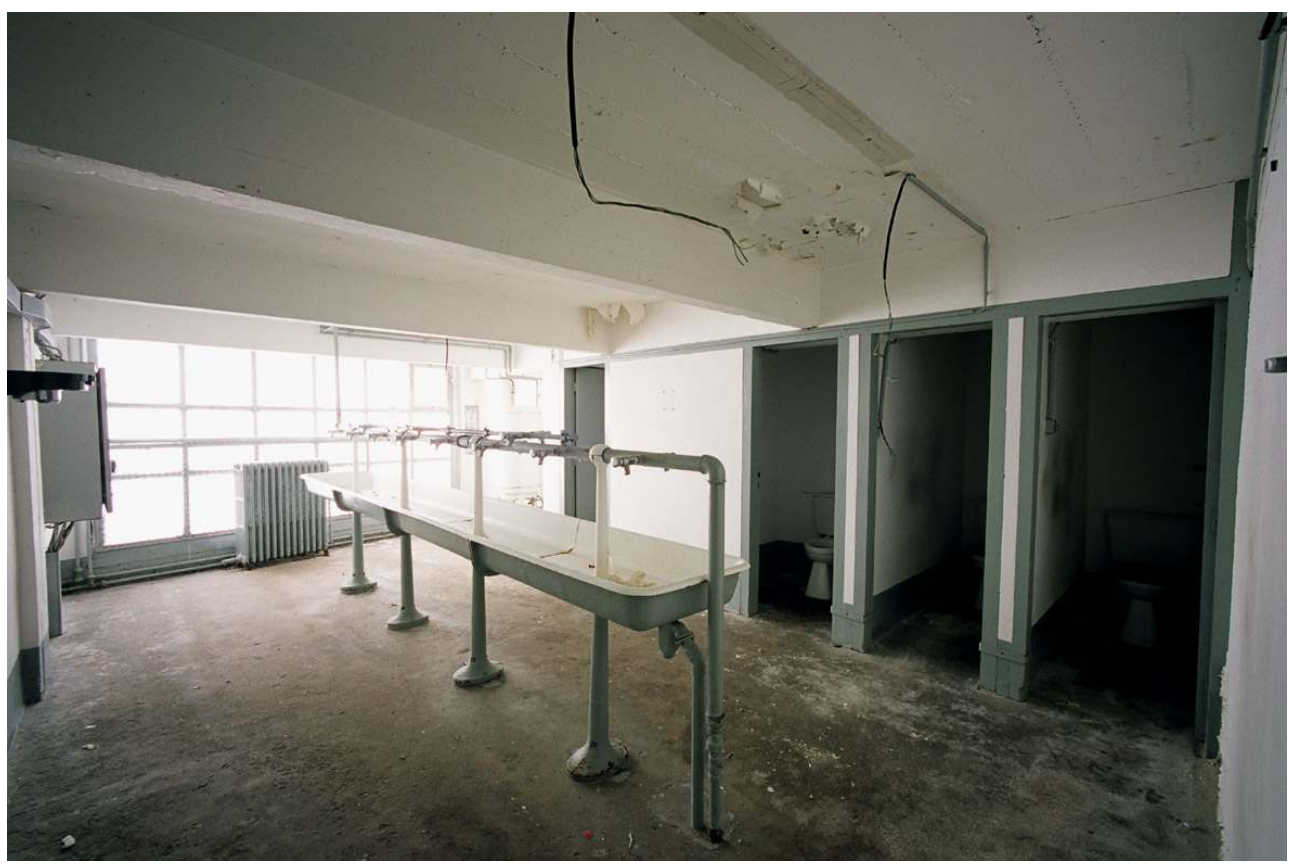

Les sanitaires des ouvrières.

Photographie Imagery, novembre 2004. Droits réservés.

61 Lorsque le musée des Pêcheries sera ouvert ${ }^{30}$, ces paroles, venues de cette expérience unique, pourront être diffusées dans cette pièce où seront par ailleurs exposés certains éléments symboliques de la fonction d'armateur (le téléphone, les portraits de navire...). Lorsque nous sommes entrées dans l'espace des lavabos (fig. $\mathbf{n}^{\circ} \mathbf{1 8}$ ), les ouvrières ont évoqué l'odeur du poisson dont elles ne pouvaient se débarrasser. Ce lieu a révélé une autre parole : celle de leur rapport à leur corps et à l'odeur forte du poisson. Elles nous ont parlé de leurs relations avec les femmes de la ville qui les méprisaient en raison de cette odeur. Nous envisageons aujourd'hui de maintenir cette pièce dans son état de désaffectation, d'abandon, et que seule y soit exposée cette parole...

\section{NOTES}

1. Cet article est largement issu d'un premier article paru dans les Annales du Patrimoine de Fécamp n¹1, 2004.

2. Nombre de recettes de régions de montagne sont réalisées à partir de morue salée.

3. La première sécherie de morue de Fécamp est créée en 1904. Il s'agit des Sécheries de morue de Fécamp dont le propriétaire est la famille Le Borgne. Voir l'article de Michel Legris, «Les sècheries de morue de Fécamp ", in Annales du Patrimoine, $n^{\circ} 6$, association Fécamp-TerreNeuve, 1999.

4. La mise en service de la Morue Normande date de mai 1928. 
5. La morue repaquée est une morue salée, retirée du stockage, mise à tremper, blanchie, puis resalée. Elle est commercialisée entière.

6. Dans les années 1880, l'adoption des doris (petites barques) favorise le développement industriel de l'activité morutière (voir catalogue de l'exposition Doris-Doris, Musée des Terreneuvas, 2001). A l'aube du XXe siècle, les morutiers n'ont jamais été aussi nombreux (en 1903, on compte 73 navires terre-neuvas à Fécamp) et dès 1905, les armateurs fécampois investissent dans des chalutiers morutiers qui vont considérablement accroître la productivité.

7. Joseph Duhamel, rapport du conseil d'administration de La Morue Normande, le 10 août 1929. Archives Municipales de Fécamp, PW 909.

8. Le style du bâtiment conçu par l'architecte parisien André Hamayon, dénote l'influence de courants novateurs (béton armé) et traditionnels (couverture en tuiles). S'inscrivant dans le contexte de la reconstruction d'après-guerre, cet immeuble incarne la confiance en l'avenir des industriels de la pêche qui comptaient vite retrouver le rang de capitale des terre-neuvas.

9. Jean York est le fils d'Honoré York. Il fut Président-directeur général des Pêcheries de Fécamp de 1968 jusqu'au rachat de l'entreprise en 1998.

10. Expression usitée à bord des morutiers et dans les ateliers de transformation du poisson pour désigner une morue insuffisamment salée et devenue impropre à la consommation.

11. Ce pourcentage était défini selon la destination du produit. Pour plus de détails sur les opérations de séchage, voir l'article de Michel Legris, cité note 3.

12. Les boucauds sont de petits barils en bois dans lesquels était conditionnée la morue séchée.

13. En général aux mois de mai, août et décembre, mais ces dates sont sujettes à des changements.

14. Voir le tableau : http://www.culture.gouv.fr/culture/inventai/telechar/tableaulevert.pdf.

15. Les saurisseries ou boucanes sont caractérisées par une série de cheminées ouvrant sur plusieurs étages afin que l'on puisse suspendre les poissons dans les conduits.

16. Ces fours de la marque Tri-sor ont été conçus par M. Martin, directeur de la Conserve fécampoise.

17. La Baader est la machine dont s'équiperont également les navires morutiers.

18. Les métiers de saleur, de saurin, ainsi que les relations entre ces différentes catégories de personnel subissent des transformations profondes qu'il faudra par ailleurs décrire et analyser dans le détail.

19. Bâtons munis de pointes sur lesquelles on pique la queue des poissons.

20. André Cadinot a été saurin à La Morue Normande pendant des années. Avant cela, il avait été saleur à bord des navires terre-neuviers avant de se reconvertir à terre dans la production de morue salée.

21. L'examen des archives relatives à la fête annuelle de la Saint-Pierre des marins de Fécamp, durant laquelle les industriels exposent leur bilan aux ministres et députés, confirme cette inquiétude (Archives municipales de Fécamp, boîte $n^{\circ} 1,1.1 .5$, Saint-Pierre des Marins).

22. Les chocs pétroliers et les quotas de pêche de plus en plus draconiens imposés par les Canadiens ont porté un coup fatal à la Grande-Pêche fécampoise. Il convient néanmoins de s'interroger sur la place de la congélation dans le contexte de la fin de la pêche morutière. C'est la morue qui a inspiré ce nouveau métier. Il a fallu tout inventer : outils, process, réseau de distribution, chaîne du froid, etc. Dans un second temps toutefois, la surgélation est devenue la véritable spécialité du groupe. La production de morue en amont n'a plus été indispensable et les navires ont désarmé sans que le groupe disparaisse. Le poisson est désormais acheté localement ou à l'étranger et on surgèle d'autres produits, comme les légumes, dont on dispose facilement.

23. J'ai entrepris une série d'enquêtes auprès des salariés et de la direction de l'ancienne usine en septembre 2003.

24. A la première époque, les ouvriers entraient dans l'usine par une porte située rue du Commandant Riondel, la porte placée à l'angle du quai de l'Entrepôt étant réservée à la direction. 
25. De ce bureau, on peut voir les bateaux entrer et sortir, observer les activités des navires dans les bassins ainsi que celles des entreprises concurrentes situées de l'autre côté du bassin de la Viconté. Ce bureau est aussi le siège de Codexnor, groupement d'intérêts fécampois pour l'exportation de la morue séchée.

26. Le triage de la morue salée était fait en deux temps. D'abord dans la cale du navire où ils vont distinguer trois tailles (c'est sur cette base que les marins seront payés) puis au rez-de-chaussée où le triage était affiné pour désigner sept tailles de poisson (c'est sur cette base que seront fixés les prix de vente).

27. Le nom de La Morue Normande a, en réalité, disparu officiellement depuis 1968. A cette date en effet, l'entreprise fusionne avec la sécherie Grand-Pêche pour former la Société Normande des Produits de la Pêche. C'est en 1978, alors que les navires sont désarmés, que les activités de négoce du groupe sont regroupées sous l'appellation « Pêcheries » qui reste l'unique raison sociale.

28. C'est rue du Commandant Riondel, dans un bâtiment adjacent à La Morue Normande, que le premier atelier de saumon s'était installé au début des années soixante. Se lancer dans la production de saumon fumé était alors une gageure. Outils, manières de faire et marché étaient à inventer. A son entrée aux Pêcheries, la production du saumon est techniquement au point.

29. Les informateurs ne s'accordent toutefois pas sur ce point. Selon certains, le troisième étage va alors abriter une activité annexe de filets de morue fabriqués à partir de cabillaud acheté frais puis salé et conditionné sur place. D'autres croient se souvenir également qu'à une époque incertaine, après l'arrêt des tunnels de séchage, l'entreprise achetait de la morue séchée en Norvège pour la conditionner et la commercialiser aux Pêcheries. Selon Jean York, en revanche, après l'arrêt des activités de production de saumon au Grand-Quai, le troisième étage a été purement et simplement « désarmé ».

30. http://www.ville-fecamp.fr/1_art-culture/musee/les-pecheries.html

\section{RÉSUMÉS}

L'usine de La Morue Normande de Fécamp est mise en service en 1950. Initialement pensée pour sécher la morue débarquée par centaines de tonnes, elle connaîtra jusqu'à sa fermeture en 1995, une large diversification. Les adaptations successives seront facilitées par la souplesse de la structure poteaux-poutres. La multiplicité des expériences qui s'y sont déroulées paraît aujourd'hui symptomatique du déclin de la pêche industrielle fécampoise. Alors qu'à l'heure actuelle coexistent une industrie de transformation qui a quitté la zone portuaire et une pêche côtière n'entretenant plus aucun lien, l'immeuble désaffecté de La Morue Normande abritera bientôt le nouveau musée de Fécamp.

In Fécamp, the factory of La Morue Normande opened in 1950. Initially created to dry cods brought by hundreds of tons, it will undergo many changes until its closing. Thank to its post-beam structure, an easy adaptation is provided. This diversification seems to be symptomatic of the decline of Fécamp industrial fishing. Nowadays, while a processing industry which left the port area a few years ago and the coastal fishing do not relate to each other anymore, the building of La Morue Normande will be soon the location of the new museum of Fécamp. 
INDEX

Mots-clés : morue, pêche industrielle, ouvriers, ouvrières, diversification, réhabilitation, musée Keywords : cod, industrial fishing, worker, diversification, reconversion, museum, La Morue Normande from cannery to museum

\section{AUTEUR}

\section{FLORENCE LEVERT}

Attachée de conservation. Musée de Fécamp. florence.levert@ville-fecamp.fr 